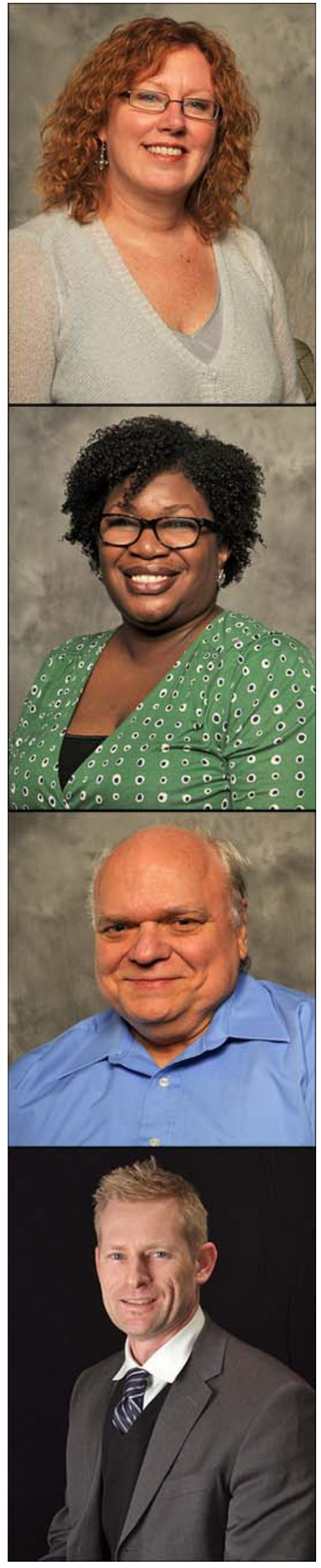

Frances McClellan, RN, MSN; Monique Washington, RN, MS; Robert Ruff, MD, PhD; Stephen M. Selkirk, MD, PhD

\section{Early and innovative symptomatic care to improve quality of life of ALS patients at Cleveland VA ALS Center}

\section{INTRODUCTION}

Amyotrophic lateral sclerosis (ALS) is a neurodegenerative disease of unknown etiology. However, there is good evidence to validate the theory that military service predisposes the individual to the future development of the disease [1]. As a direct result of these data, in 2008 ALS became a presumptively compensable illness for all veterans with 90 days or more of continuously active service in the military. This decision led to an influx of ALS patients into the Department of Veterans Affairs (VA) healthcare system and the development of a nationwide plan of care [2]. The implementation of this plan at the Cleveland VA Spinal Cord Injury (SCI) Division has been challenging. However, it has offered the opportunity to review current practice parameters that dictate the care of ALS patients in a new context. Using these parameters and considering the strengths and weakness of the VA healthcare system, we have made significant improvements to current practice and applied novel technology to care for ALS patients. Herein we describe these innovations and the foundation we have established to provide high quality ALS care.

\section{BACKGROUND}

ALS is a terminal neurodegenerative disorder. The management of patients with ALS centers almost entirely around symptomatic care. Although many studies have examined the role of particular interventions in prolonging survival after diagnosis or decreasing the rate of decline in physical ability, perhaps the most important studies guiding intervention have investigated quality of life (QoL) over the course of the disease. In 1999, the American Academy of Neurology (AAN) published the first set of formal practice parameters based on a review of the literature [3]. These evidencebased practice parameters were revised in 2009 [4] and included important updates on how care is administered, as well as recommendations regarding the use of the first disease-modifying agent available. The European Federation of Neurological Societies (EFNS) published parallel recommendations in 2005 [5], with revised and updated practice guidelines published in 2012 [6]. A third publication in 2007 also summarized current evidence-based recommendations for care of ALS patients [7]. These three sets of recommendations are nearly identical and in many instances lack precise details in 
terms of when and how to implement care. This reveals a need for further studies to answer basic questions regarding interventions, such as when a percutaneous endoscopic gastrostomy (PEG) tube should be placed in a patient or how early respiratory support should be provided. This information would help standardize practice parameters and allow for a higher level of symptomatic care in patients with ALS.

\section{INNOVATIVE CARE IN VA SYSTEM}

\section{Early Noninvasive Positive Pressure Ventilation for ALS Patients}

The majority of patients with ALS will die from respiratory failure [8]. Furthermore, during the course of the disease, respiratory function correlates with QoL and patient survival [9-11]. The survival benefits from noninvasive positive pressure ventilation (NIPPV) supersede those obtained from riluzole or PEG tube insertion [12]. It follows, logically, that aggressive management of respiratory compromise should be part of a comprehensive plan not simply to prolong life (because some patients prefer not to have their life prolonged) but also as a mechanism to improve QoL. The latter goal, which is more consistent with our mission as an ALS center, is supported by several well-designed studies [12-13]. These studies suggest that NIPPV improves QoL by improving a patient's energy, concentration, and sleep quality, decreasing daytime somnolence and physical fatigue. NIPPV also improves lung compliance [14] and decreases the rate of decline in vital capacity [15-16]. Despite this evidence, the ALS Clinical Assessment Research and Education database has documented underutilization of NIPPV by patients with ALS [17].

As we developed our system of care in the VA system, we attempted to identify barriers to NIPPV utilization in our patients. The first identified problem, and easiest to remedy, was that patients were not being offered NIPPV at their previous treatment centers [18]. We therefore developed a template for our physician to discuss options for respiratory intervention at the patient's initial visit. The inter- ventions and outcomes are discussed, and educational material is provided for the patient as well. The second barrier, not unique to the VA system, was patient compliance with NIPPV. NIPPV is difficult to use for many ALS patients; studies show documented compliance in less than 65 percent of patients, with compliance decreasing to 25 percent in patients with concomitant frontal temporal dementia [19] or bulbar onset disease [20]. To improve compliance, we developed several strategies used in tandem. First, if the asymptotic patient with normal or only mildly compromised pulmonary function expresses a desire to use NIPPV in the future, he or she undergoes a modified sleep study and is issued a device as soon as possible. This early administration is coupled with the advice to start using the machine for brief periods of time while relaxing and aggressive home respiratory support. Patients have a respiratory therapist visit to instruct them regarding use and inquire about comfort. This allows for early intervention to modify administration, thereby improving compliance. Furthermore, patients are reevaluated by the sleep medicine specialist every 3 months, at which time compliance is determined by interrogating data from the device and making modifications.

The concept of early NIPPV is not novel and there is evidence to support implementation. Lechtzin et al. reported a retrospective study on 102 ALS patients and found a survival advantage of 1 year in those provided intervention early (forced vital capacity [FVC] > 65\%) [21]. Pinto et al. presented similar data in patients who were started on NIPPV because of nocturnal desaturations but not diminished FVC [22]. Patients in this study receiving early intervention also survived longer than those provided the intervention later. Patients provided early NIPPV (FVC > 65\%) also have been found to be more compliant with device utilization [23]. Finally, Gruis et al. have shown that improving QoL by only 13.5 percent would justify the cost of initiating NIPPV at the time of diagnosis rather than when it is currently recommended [24].

The current practice parameters recommend initiating NIPPV when the patient's FVC reaches 50 percent predicted or the patient complains of shortness 
of breath [4]. Other measured parameters, including sniff nasal pressure (SNP) and maximal inspiratory pressure (MIP), are also recommended as potential data that can be used to initiate NIPPV [4]. However, high-quality data supporting the timing of NIPPV initiation (FVC $<50 \%$, SNP $<40 \mathrm{~cm}$, or MIP $<60 \mathrm{~cm}$ ) are not available. Interestingly, the EFNS guidelines state, "there is no clear evidence regarding the timing . . . for use of NIPPV” [6]. Another contributing factor to the current recommended timing of intervention may be Medicare guidelines that limit coverage of NIPPV to patients with a diagnosis of neuromuscular disease and FVC $<50$ percent.

We recommend NIPPV be initiated at the earliest possible time point, with the highest level of ongoing support to encourage compliance. There is no evidence to wait until a patient's FVC is significantly compromised and no evidence to suggest that early intervention is harmful to patients. In contrast, there is evidence to suggest that early NIPPV prolongs survival and promotes compliance with treatment.

\section{Diaphragm Pacemaker Implantation for ALS Patients}

In September 2011 under a Humanitarian Device Exemption, the Food and Drug Administration approved diaphragmatic pacing (DP) using direct intramuscular electrodes for the treatment of respiratory failure in patients with ALS. DP had already been approved for use under a Humanitarian Device Exemption for patients with high-level SCI and ventilator dependence [25]. Its use in this population has been shown to support ventilator independence and improve QoL [26-27]. The first ALS patient was implanted in 2005. The number of patients implanted since that time has been relatively limited, and the information available regarding the potential benefit to ALS patients has been equally limited. In 2007, a poster was presented detailing results of 16 implants [28]. The report demonstrated an increase in survival time in those implanted when compared with historic controls and a decrease in the rate of FVC decline after implantation compared with before. However, important details were not presented, including the source of the control group data. In 2009, this cohort was again reported on in greater detail with a second cohort of 20 patients [28]. Further details were later published in separate reports [27,29]. In this report, FVC decline decreased from 2.4 percent per month to 0.9 percent per month. This was extrapolated to an increased survival time of $24 \mathrm{mo}$ and a delay in need for artificial ventilation by 24 mo. However, some have suggested that the absence of important details makes it difficult to interpret the true significance of these results [30].

We have offered DP implantation to six veterans with ALS (Table 1) based on the original publication and the same cohort described in the 2009 article because of perceived low risk of complications and no evidence of a negative effect on survival time [2728]. To date, we have had six patients implanted simultaneously with DP and gastrostomy tube. DP implantation occurred early because the average FVC was 83 percent at implantation. Although our cohort size is limited and follow-up times vary, the change in respiratory insufficiency scores has been minimal for these patients and survival time from diagnosis appears prolonged (Table 1). This further suggests

\section{Table 1.}

Diaphragmatic pacing (DP). Six patients were implanted simultaneously with percutaneous endoscopic gastrostomy (PEG) and DP. Patients tolerated procedure without complication, although usage of device varied as disease progressed and scores of respiratory insufficiency declined minimally.

\begin{tabular}{lc}
\hline \multicolumn{1}{c}{ Characteristic } & Result \\
\hline Rate of DP Acceptance, \% ( $n)$ & $100(6)$ \\
Time to DP Implantation, ${ }^{*}$ days (mean \pm SD) & $581 \pm 441$ \\
ALSFRS-R ${ }^{\dagger}$ at DP Implantation (mean \pm SD) & $30.00 \pm 9.14$ \\
ALSFRS-R Respiratory Insufficiency ${ }^{\ddagger}$ at & $3.00 \pm 1.09$ \\
$\quad$ Implantation (mean \pm SD) & \\
ALSFRS-R Respiratory Insufficiency at & $2.50 \pm 0.83$ \\
Follow-Up ${ }^{\S}$ (mean \pm SD) & \\
Average FVC at DP Implant, \% (mean \pm SD) & $83.00 \pm 0.24$ \\
${ }^{*}$ Time from ALS diagnosis to accepting elective DP placement. \\
${ }^{\dagger}$ ALSFRS-R scores range from 0 to 48, with lower scores indicating greater \\
disability. \\
${ }^{\ddagger}$ ALSFRS-R Respiratory Insufficiency scores range from 0 to 4, with lower \\
scores indicating greater respiratory insufficiency. \\
§Follow-up is most recent visit and variable for each patient. \\
ALSFRS-R = Amyotrophic Lateral Sclerosis Function Rating Scale-Revised, \\
DP = diaphragmatic pacing, FVC = forced vital capacity, SD = standard \\
deviation.
\end{tabular}


that DP may be beneficial. No complications other than mild discomfort when using the system have been reported to us. Given the lack of high-quality data regarding potential benefit to patients, we have been cautiously optimistic regarding our own patient population and plan on retrospectively reviewing survival compared with NIPPV patients matched appropriately in the near future.

\section{Early Percutaneous Endoscopic Gastrostomy Tube Placement}

PEG tube placement is an important intervention as ALS progresses. Weight loss at the time of diagnosis independently predicts survival, underscoring the importance of maintaining nutritional status in ALS patients [31]. Enteral nutrition administered using a PEG tube has been shown to stabilize a patient's nutritional status [32] and prolong survival [32-33]. The number of months survival is prolonged by PEG intervention is not clear but ranges from 3 to 8 months and likely depends on the degree of bulbar involvement the patient has [34]. The overall effect of PEG tube insertion on QoL remains somewhat controversial. The 2009 AAN practice parameters conclude that insufficient data were available to support improved QoL in patients with PEG [4]. The European task force recommendations reiterated this position [6]. Although various reports suggest a significant decrease in the decline in QoL as the disease progresses in patients after PEG tube implantation [35], there are an equal number of published reports that fail to replicate this result [36]. In contrast, there is no evidence to suggest that PEG tube insertion and enteral nutrition decrease QoL or decrease survival time.

One of the most difficult decisions regarding a PEG tube is when it should be inserted. Unfortunately, there is no good evidence to help guide providers' or patients' decision-making process. The AAN practice parameters state that there is not enough evidence to support or refute a specific timing of PEG tube insertion [4]. The EFNS Task Force recommends that the decision be individualized based on multiple factors, including bulbar symptoms, weight loss, and respiratory function [6]. However, this publication goes on to state, "early insertion ... . is recom- mended.” Although the precise time that PEG tube insertion should occur is unknown, we do know that when FVC declines below 50 percent of predicted, the risk of complications increases significantly [3739]. These complications include respiratory failure requiring permanent ventilation. This outcome is particularly worrisome to those patients who desire PEG tube insertion but not artificial ventilation. In our experience, this represents the majority of patients. As expected, published reports suggest higher rates of morbidity and mortality in ALS patients compared with other patients undergoing PEG tube insertion. Beggs et al. published a review of 69 ALS patients and documented a postprocedure infection rate of 7.2 percent, with 1.4 percent developing peritonitis [40]. Bigard and Champigneulle reported a mortality rate of 0.6 percent in the general population [41] compared with reported mortality in ALS patients as high as 11.9 percent [42]. In our cohort, 77 percent of patients accepted and successfully underwent PEG tube placement (Table 2). ALS patients receiving elective PEG tube placement at our center had very low rates of complications (Tables 3 and 4); no mortalities have occurred. The most common minor complication was leakage around the PEG tube, occurring in 10 percent of patients. Two patients requested a revision to a button PEG tube (Table 4). We were unable to insert a PEG tube in two patients, and one patient had successful insertion only after the second endoscopic attempt. The low complication rate in elective PEG tube placement is likely related to the FVC of our patients at the time of the procedure. The average FVC in our cohort was 69 percent of predicted measured within 30 days of the procedure, and

Table 2.

Percutaneous endoscopic gastrostomy (PEG) tube placement. Majority of patients offered elective PEG tube placement were agreeable and were implanted before forced vital capacity (FVC) reached 50\%.

\begin{tabular}{lc}
\hline \multicolumn{1}{c}{ Characteristic } & Result \\
\hline Rate of PEG Tube Acceptance, \% (n) & $77(28)$ \\
Time to PEG Placement, ${ }^{*}$ days (mean \pm SD) & $421 \pm 381$ \\
Average FVC at PEG Placement, \% (mean \pm SD) & $69.00 \pm 29.85$ \\
\hline *Time from ALS diagnosis to elective PEG placement. \\
SD = standard deviation. \\
\hline \hline
\end{tabular}


Table 3.

Percutaneous endoscopic gastrostomy (PEG). Patients did not have any acute complications after PEG implantation. Long-term complications occurred in $18 \%$ of patients, but were all minor.

\begin{tabular}{lccc}
\hline \multicolumn{1}{c}{ Characteristic } & $\begin{array}{c}\text { Total } \\
\text { Population } \\
(\boldsymbol{n}=\mathbf{2 8})\end{array}$ & $\begin{array}{c}\text { Elective } \\
\text { PEG } \\
(\boldsymbol{n}=\mathbf{2 3})\end{array}$ & $\begin{array}{c}\text { FVC } \\
<\mathbf{5 0 \%}\end{array}$ \\
\hline $\begin{array}{l}\text { Acute Complication, } \\
\%(n)\end{array}$ & $0.0(0)$ & $0.0(0)$ & $0.0(0)$ \\
$\begin{array}{l}\text { Late Complication, } \\
\%(n)\end{array}$ & $17.9(5)$ & $17.4(4)$ & $12.5(1)$ \\
\hline FVC = forced vital capacity. & & & \\
\hline \hline
\end{tabular}

Table 4.

Percutaneous endoscopic gastrostomy (PEG) complications. Most common long-term complication was leakage around PEG site. One patient developed cellulitis at PEG site, but this occurred 8 mo after implantation.

\begin{tabular}{lc}
\hline \multicolumn{1}{c}{ Complication } & Result \\
\hline Acute Complication, \% (n) & $100(28)$ \\
None & \\
Late Complication, \% (n) & $82.1(23)$ \\
None & $7.1(2)$ \\
Requested Revisions & $10.7(3)$ \\
Leakage & $3.6(1)$ \\
Cellulitis
\end{tabular}

only two patients had an FVC $<50$ percent at the time of insertion (Table 2). Notably, in both cases in which we were unable to insert a PEG tube, the patients presented late in the disease course and FVC was $<30$ percent.

In summary, we recommend PEG tube insertion at the earliest time point possible. The role of PEG tube insertion is discussed at the initial visit to our clinic, with emphasis on the importance of early insertion. If a patient is accepting, insertion is planned when consecutive pulmonary function tests (performed every 3 months) demonstrate a decline in FVC or routine screening modified barium swallow (MBS) studies (every 3 months) demonstrate abnormalities. There seems to be no good reason to delay insertion until FVC approaches 50 percent, particularly if button PEG tubes are being used. Delayed insertion simply increases the potential for complications, including the possibility of inadvertent artificial ventilation. Using this system, we have greatly limited morbidity and mortality relative to what has been reported in other ALS cohorts.

\section{Telemedicine and Mobile Video Consultation}

Telemedicine is a rapidly evolving application of healthcare that allows patients to interact with healthcare providers using telecommunication technology. In the VA system, telemedicine allows patients to present to a local VA and interact with our healthcare providers at the Cleveland ALS Center. This is done in the presence of the local VA healthcare team. This team then coordinates care locally for the patient and notifies the ALS center of results so that further recommendations can be made. An extension of this technology is mobile video consultation. Mobile video consultation is a secure, encrypted Skype-like system, whereby patients can interact with healthcare providers at the Cleveland ALS Center from their home computer. This is utilized by patients with slowly progressive disease or advanced disease when regular testing (pulmonary function tests or MBS evaluations) is not required. The primary advantage of this technology is avoiding travel while maintaining access to the care provided by an ALS center. The value of this approach becomes more evident as the disease progresses and patients become functionally tetraplegic, requiring a wheelchair and wheelchairaccessible vehicle or ambulance. Furthermore, as the disease progresses, bulbar involvement generally requires access to suction devices, cough assistive devices, and constant NIPPV or ventilator support. Organizing this level of transport is extremely complex and expensive and not available to all patients at all centers. The importance of this type of access to an ALS center has been demonstrated previously [43].

There is only one publication addressing the utility of this technology in ALS patients. Pinto et al. reported that in ventilated ALS patients, home telemonitoring resulted in decreased emergency room visits and hospital admissions, with a trend toward increased survival [22]. We are currently following eight patients via telemedicine and four patients using mobile video consultation. We are following QoL, satisfaction with care, and survival time data in these patients to determine the usefulness of the technology in providing access to ALS 
specialty care to patients at a distance or to patients with significant disability prohibiting travel to the center. We calculate that using this technology has saved $\$ 34,137$ in travel costs over the last year (Table 5).

We recommend the use of telemedicine and mobile video technologies to allow access to specialty care at ALS centers for patients who live at distances that prohibit routine care or who have advanced in the disease process, making travel complicated, costly, and dangerous.

\section{Equipment Reutilization}

A final innovation unique to the VA system is durable medication equipment (DME) reuse. Because of the high cost of wheelchairs, respiratory equipment, and communication devices, we considered programs to improve efficiency at reduced costs. Working with our prosthetics department, we developed a program to recoup equipment that was issued to veterans with ALS but no longer in use and then reissue it to other ALS patients.

One of the most expensive items issued to patients with ALS by prosthetists is a motorized wheelchair. Wheelchairs for ALS patients are often custom-designed with alternate driving systems, ventilator trays, and elevating and tilting features. These features are unique to ALS patients (or high tetraplegic patients) and not used by all power wheelchair users. We established a protocol in which these custom wheelchairs are retrieved at end of life, cleaned, repaired, and stored separately from general power chairs at the DME warehouse. These custom wheelchairs can then be accessed and reused for

Table 5.

Estimated reduction in healthcare costs. Telemedicine technology and equipment reutilization resulted in significant cost savings over last 24 mo.

\begin{tabular}{lc}
\hline \multicolumn{1}{c}{ Item } & Cost Savings (\$) \\
\hline Travel Expenses & 34,137 \\
Biphasic Positive Airway Pressure & 45,320 \\
Pulmonary Vest & 107,747 \\
Wheel Chair & 55,500 \\
Speech Device & 36,000 \\
Total Annual Savings & 278,704 \\
\hline \hline
\end{tabular}

other individuals with ALS. This allows our seating specialist to fit the pre-existing wheelchair to another patient without having to start from a base power chair. When a wheelchair is available, it reduces time required to issue a chair from 6 to 8 weeks to 2 to 3 weeks and substantially reduces the cost. The estimated savings from four re-issued power chairs was \$55,500 (Table 5).

Another commonly distributed category of DME is respiratory equipment. This includes biphasic positive airway pressure machines, cough-assistive devices, and pulmonary vests. In addition to the expense, delivery to patients was inefficient and, coupled with a need for in-home training, resulted in a significant time between the point of requesting this equipment to the time it could actually be used by the patient. In order to reduce cost, we began renting the equipment. This decision was consistent with the expected life span and prognosis of our patient population. We have also maintained a limited number of biphasic positive airway pressure devices in stock at our facility so that when a patient completes a sleep study, the device can be given to the patient on the same day. Our vendor then goes out to the home shortly thereafter to ensure compliance, comfort, and use, but also to replace the unit with a rental. The VA's unit is then returned, properly cleaned, and reused. Pulmonary vests and cough-assistive devices are also rented instead of purchased and delivered directly to the home by the vendor, reducing costs. Since initiating this program of renting and reusing respiratory equipment, we have saved approximately \$153,067 (Table 5).

Finally, communication devices are also expensive and customized for patients with ALS. These units are retrieved at end of life and can be cleaned and reissued at a significant cost savings. This has been a recent addition to our reuse program, and we have currently re-issued two devices, saving approximately \$36,000 (Table 5).

The overall cost savings from our program over the last year is approximately $\$ 278,704$ (Table 5). 


\section{CONCLUSIONS}

The development of an ALS system of care in the VA system has led to unique opportunities to improve symptomatic care for patients. Many of the constraints that exist in the private sector are not relevant in the VA system, allowing for early NIPPV administration and increased access to DP placement. The VA system also has technologies such as telemedicine, which is not routinely available in the private sector but has significantly altered how we care for our patients. We hope that as we continue to develop these technologies and implement our care plan we can demonstrate the ability to improve QoL in ALS patients and ultimately change the way in which ALS care is delivered in both the VA system and the private sector.

\section{Frances McClellan, RN, MSN; ${ }^{1}$ Monique Washing- ton, $R N, M S ;^{1}$ Robert Ruff, MD, PhD $;^{2-3}$ Stephen M. Selkirk, $M D, P h D^{1,3 *}$}

${ }^{1}$ Spinal Cord Injury Division and ${ }^{2}$ Department of Neurology, Louis Stokes Cleveland VA Medical Center, Cleveland, $\mathrm{OH} ;{ }^{3}$ Case Western Reserve Medical School, Department of Neurology, Cleveland, $\mathrm{OH}$

*Email: stephen.selkirk@va.gov

\section{ACKNOWLEDGMENT}

Disclaimer: The views expressed in this article are those of the authors and do not necessarily represent the position or policy of VA or the Department of Defense.

\section{REFERENCES}

1. Weisskopf MG, O’Reilly EJ, McCullough ML, Calle EE, Thun MJ, Cudkowicz M, Ascherio A. Prospective study of military service and mortality from ALS. Neurology. 2005;64(1):32-37. [PMID:15642900] http://dx.doi.org/10.1212/01.WNL.0000148649.17706.D9

2. Ruff R. Amyotropic lateral sclerosis system of care procedures. Washington (DC): VHA; 2013.

3. Miller RG, Jackson CE, Kasarskis EJ, England JD, Forshew D, Johnston W, Kalra S, Katz JS, Mitsumoto
H, Rosenfeld J, Shoesmith C, Strong MJ, Woolley SC; Quality Standards Subcommittee of the American Academy of Neurology. Practice parameter: the care of the patient with amyotrophic lateral sclerosis: drug, nutritional, and respiratory therapies (an evidencebased review): report of the Quality Standards Subcommittee of the American Academy of Neurology. Neurology. 1999;52(7):1311-23. [PMID:10227612] http://dx.doi.org/10.1212/WNL.52.7.1311

4. Miller RG, Jackson CE, Kasarskis EJ, England JD, Forshew D, Johnston W, Kalra S, Katz JS, Mitsumoto H, Rosenfeld J, Shoesmith C, Strong MJ, Woolley SC; Quality Standards Subcommittee of the American Academy of Neurology. Practice parameter update: the care of the patient with amyotrophic lateral sclerosis: drug, nutritional, and respiratory therapies (an evidence-based review): report of the Quality Standards Subcommittee of the American Academy of Neurology. Neurology. 2009;73(15): 1218-26. [PMID:19822872] http://dx.doi.org/10.1212/WNL.0b013e3181bc0141

5. Andersen PM, Borasio GD, Dengler R, Hardiman O, Kollewe K, Leigh PN, Pradat PF, Silani V, Tomik B; EFNS Task Force on Diagnosis and Management of Amyotrophic Lateral Sclerosis. EFNS task force on management of amyotrophic lateral sclerosis: guidelines for diagnosing and clinical care of patients and relatives. Eur J Neurol. 2005;12(12):921-38.

[PMID:16324086] http://dx.doi.org/10.1111/j.1468-1331.2005.01351.x

6. Andersen PM, Abrahams S, Borasio GD, de Carvalho M, Chio A, Van Damme P, Hardiman O, Kollewe K, Morrison KE, Petri S, Pradat PF, Silani V, Tomik B, Wasner M, Weber M; EFNS Task Force on Diagnosis and Management of Amyotrophic Lateral Sclerosis. EFNS guidelines on the clinical management of amyotrophic lateral sclerosis (MALS) revised report of an EFNS task force. Eur J Neurol. 2012;19(3):360-75. [PMID:21914052] http://dx.doi.org/10.1111/j.1468-1331.2011.03501.x

7. Andersen PM, Borasio GD, Dengler R, Hardiman O, Kollewe K, Leigh PN, Pradat PF, Silani V, Tomik B; EALSC Working Group. Good practice in the management of amyotrophic lateral sclerosis: clinical guidelines. An evidence-based review with good practice points. Amyotroph Lateral Scler. 2007;8(4): 195-213. [PMID:17653917] http://dx.doi.org/10.1080/17482960701262376 
8. Rowland LP, Shneider NA. Amyotrophic lateral sclerosis. N Engl J Med. 2001;344(22):1688-1700. [PMID:11386269] http://dx.doi.org/10.1056/NEJM200105313442207

9. Bourke SC, Shaw PJ, Gibson GJ. Respiratory function vs sleep-disordered breathing as predictors of QOL in ALS. Neurology. 2001;57(11):2040-44. [PMID:11739823]

http://dx.doi.org/10.1212/WNL.57.11.2040

10. Desport JC, Preux PM, Truong TC, Vallat JM, Sautereau D, Couratier P. Nutritional status is a prognostic factor for survival in ALS patients. Neurology. 1999;53(5):1059-63. [PMID:10496266] http://dx.doi.org/10.1212/WNL.53.5.1059

11. Louwerse ES, Visser CE, Bossuyt PM, Weverling GJ; The Netherlands ALS Consortium. Amyotrophic lateral sclerosis: mortality risk during the course of the disease and prognostic factors. J Neurol Sci. 1997;152(Suppl 1):S10-17. [PMID:9419048] http://dx.doi.org/10.1016/S0022-510X(97)00238-4

12. Bourke SC, Tomlinson M, Williams TL, Bullock RE, Shaw PJ, Gibson GJ. Effects of non-invasive ventilation on survival and quality of life in patients with amyotrophic lateral sclerosis: a randomised controlled trial. Lancet Neurol. 2006;5(2):140-47. [PMID:16426990] http://dx.doi.org/10.1016/S1474-4422(05)70326-4

13. Jackson CE, Rosenfeld J, Moore DH, Bryan WW, Barohn RJ, Wrench M, Myers D, Heberlin L, King R, Smith J, Gelinas D, Miller RG. A preliminary evaluation of a prospective study of pulmonary function studies and symptoms of hypoventilation in ALS/MND patients. J Neurol Sci. 2001;191(1-2): 75-78. [PMID:11676995]

http://dx.doi.org/10.1016/S0022-510X(01)00617-7

14. Lechtzin N, Shade D, Clawson L, Wiener CM. Supramaximal inflation improves lung compliance in subjects with amyotrophic lateral sclerosis. Chest. 2006;129(5):1322-29. [PMID:16685025] http://dx.doi.org/10.1378/chest.129.5.1322

15. Scanlon PD, Loring SH, Pichurko BM, McCool FD, Slutsky AS, Sarkarati M, Brown R. Respiratory mechanics in acute quadriplegic. Lung and chest wall compliance and dimensional changes during respiratory maneuvers. Am Rev Respir Dis. 1989; 139:615-20. [PMID:2923360] http://dx.doi.org/10.1164/ajrccm/139.3.615

16. De Troyer A, Borenstein S, Cordier R. Analysis of lung volume restriction in patients with respiratory muscle weakness. Thorax. 1980;35(8):603-10.

\section{[PMID:7444828]}

http://dx.doi.org/10.1136/thx.35.8.603

17. Bradley WG, Anderson F, Bromberg M, Gutmann L, Harati Y, Ross M, Miller RG; ALS CARE Study Group; The American Academy of Neurology. Current management of ALS: comparison of the ALS CARE Database and the AAN Practice Parameter. Neurology. 2001;57(3):500-4. [PMID:11502920] http://dx.doi.org/10.1212/WNL.57.3.500

18. McClellan F, Washington M, Ruff R, Selkirk SM. Developing a system of care for ALS patients at the Louis Stokes Cleveland VA Medical Center, Spinal Cord Injury Division. J Rehabil Res Dev. 2013; 50(2):vii-Xvii.

19. Olney RK, Murphy J, Forshew D, Garwood E, Miller BL, Langmore S, Kohn MA, Lomen-Hoerth C. The effects of executive and behavioral dysfunction on the course of ALS. Neurology. 2005;65(11): 1774-77. [PMID:16344521] http://dx.doi.org/10.1212/01.wnl.0000188759.87240.8b

20. Gelinas DF, O’Connor P, Miller RG. Quality of life for ventilator-dependent ALS patients and their caregivers. J Neurol Sci. 1998;160(Suppl 1):S134-36. [PMID:9851663] http://dx.doi.org/10.1016/S0022-510X(98)00212-3

21. Lechtzin N, Scott Y, Busse AM, Clawson LL, Kimball R, Wiener CM. Early use of non-invasive ventilation prolongs survival in subjects with ALS. Amyotroph Lateral Scler. 2007;8(3):185-88. [PMID:17538782] http://dx.doi.org/10.1080/17482960701262392

22. Pinto A, Almeida JP, Pinto S, Pereira J, Oliveira AG, de Carvalho M. Home telemonitoring of non-invasive ventilation decreases healthcare utilisation in a prospective controlled trial of patients with amyotrophic lateral sclerosis. J Neurol Neurosurg Psychiatry. 2010; 81(11):1238-42. [PMID:20826878] http://dx.doi.org/10.1136/jnnp.2010.206680

23. Jackson CE, Rosenfeld J, Moore DH, Bryan WW, Barohn RJ, Wrench M, Myers D, Heberlin L, King R, Smith J, Gelinas D, Miller RG. A preliminary evaluation of a prospective study of pulmonary function studies and symptoms of hypoventilation in ALS/ MND patients. J Neuro Sci. 2001;191(1-2):75-78. [PMID:11676995] http://dx.doi.org/10.1016/S0022-510X(01)00617-7

24. Gruis KL, Chernew ME, Brown DL. The costeffectiveness of early noninvasive ventilation for ALS patients. BMC Health Serv Res. 2005;5:58-62. 
[PMID:16131401]

http://dx.doi.org/10.1186/1472-6963-5-58

25. DiMarco AF, Onders RP, Kowalski KE, Miller ME, Ferek S, Mortimer JT. Phrenic nerve pacing in a tetraplegic patient via intramuscular diaphragm electrodes. Am J Respir Crit Care Med. 2002;166(12 Pt 1):1604-6. [PMID:12471076] http://dx.doi.org/10.1164/rccm.200203-175CR

26. DiMarco AF, Onders RP, Ignagni A, Kowalski KE, Mortimer JT. Phrenic nerve pacing via intramuscular diaphragm electrodes in tetraplegic subjects. Chest. 2005;127(2):671-78. [PMID:15706014] http://dx.doi.org/10.1378/chest.127.2.671

27. Onders RP, Elmo M, Khansarinia S, Bowman B, Yee J, Road J, Bass B, Dunkin B, Ingvarsson PE, Oddsdóttir M. Complete worldwide operative experience in laparoscopic diaphragm pacing: results and differences in spinal cord injured patients and amyotrophic lateral sclerosis patients. Surg Endosc. 2009;23(7): 1433-40. [PMID:19067067]

http://dx.doi.org/10.1007/s00464-008-0223-3

28. Onders RP, Schilz R, Katirji B, Elmo M, Ignagni A. Motor point diaphragm pacing in patients with MDN/ ALS: long term follow-up of completed safety and feasibility study. Amyotroph Lateral Scler. 2007;5:82.

29. Schmiesing CA, Lee J, Morton JM, Brock-Utne JG. Laparoscopic diaphragmatic pacer placement-a potential new treatment for ALS patients: a brief description of the device and anesthetic issues. J Clin Anesth. 2010;22(7):549-52. [PMID:21056813] http://dx.doi.org/10.1016/j.jclinane.2009.09.010

30. Scherer K, Bedlack RS. Diaphragm pacing in amyotrophic lateral sclerosis: a literature review. Muscle Nerve. 2012;46(1):1-8. [PMID:22692995] http://dx.doi.org/10.1002/mus.23419

31. Marin B, Desport JC, Kajeu P, Jesus P, Nicolaud B, Nicol M, Preux PM, Couratier P. Alteration of nutritional status at diagnosis is a prognostic factor for survival of amyotrophic lateral sclerosis patients. J Neurol Neurosurg Psychiatry. 2011;82(6):628-34. [PMID:21097551] http://dx.doi.org/10.1136/jnnp.2010.211474

32. Bensimon G, Lacomblez L, Meininger V; ALS/Riluzole Study Group. A controlled trial of riluzole in amyotrophic lateral sclerosis. N Engl J Med. 1994; 330(9):585-91. [PMID:8302340] http://dx.doi.org/10.1056/NEJM199403033300901

33. Forshew DA, Bromberg MB. A survey of clinicians' practice in the symptomatic treatment of ALS. Amyo- troph Lateral Scler Other Motor Neuron Disord. 2003; 4(4):258-63. [PMID:14753660] http://dx.doi.org/10.1080/14660820310017344

34. Spataro R, Ficano L, Piccoli F, La Bella V. Percutaneous endoscopic gastrostomy in amyotrophic lateral sclerosis: effect on survival. J Neurol Sci. 2011; 304(1-2):44-48. [PMID:21371720] http://dx.doi.org/10.1016/j.jns.2011.02.016

35. Lou JS, Moore D, Gordon PH, Miller R. Correlates of quality of life in ALS: Lessons from the minocycline study. Amyotroph Lateral Scler. 2010;11(1-2):116-21. [PMID:19551536] http://dx.doi.org/10.3109/17482960902918719

36. Zamietra K, Lehman EB, Felgoise SH, Walsh SM, Stephens HE, Simmons Z. Non-invasive ventilation and gastrostomy may not impact overall quality of life in patients with ALS. Amyotroph Lateral Scler. 2012;13(1):55-58. [PMID:22214353] http://dx.doi.org/10.3109/17482968.2011.641570

37. Kasarskis EJ, Scarlata D, Hill R, Fuller C, Stambler $\mathrm{N}$, Cedarbaum JM. A retrospective study of percutaneous endoscopic gastrostomy in ALS patients during the BDNF and CNTF trials. J Neurol Sci. 1999; 169(1-2):118-25. [PMID:10540019] http://dx.doi.org/10.1016/S0022-510X(99)00230-0

38. Desport JC, Preux PM, Truong CT, Courat L, Vallat JM, Couratier P. Nutritional assessment and survival in ALS patients. Amyotroph Lateral Scler Other Motor Neuron Disord. 2000;1(2):91-96. [PMID:11467055] http://dx.doi.org/10.1080/14660820050515386

39. Heffernan C, Jenkinson C, Holmes T, Feder G, Kupfer R, Leigh PN, McGowan S, Rio A, Sidhu P. Nutritional management in MND/ALS patients: an evidence based review. Amyotroph Lateral Scler Other Motor Neuron Disord. 2004;5(2):72-83. [PMID:15204009] http://dx.doi.org/10.1080/14660820410020349

40. Beggs K, Choi M, Travlos A. Assessing and predicting successful tube placement outcomes in ALS patients. Amyotroph Lateral Scler. 2010;11(1-2):203-6. [PMID:19714540] http://dx.doi.org/10.3109/17482960903207377

41. Bigard MA, Champigneulle B. [A role for percutaneous endoscopic gastrostomy]. Gastroenterol Clin Biol. 1987;11(10):659-62. French. [PMID:3121429]

42. Strong MJ, Rowe A, Rankin RN. Percutaneous gastrojejunostomy in amyotrophic lateral sclerosis. J Neurol Sci. 1999;169(1-2):128-32. [PMID:10540021] http://dx.doi.org/10.1016/S0022-510X(99)00235-X 
JRRD, Volume 50, Number 4, 2013

43. Chiò A, Bottacchi E, Buffa C, Mutani R, Mora G; PARALS. Positive effects of tertiary centres for amyotrophic lateral sclerosis on outcome and use of hospital facilities. J Neurol Neurosurg Psychiatry. 2006;77(8):948-50. [PMID:16614011]

http://dx.doi.org/10.1136/jnnp.2005.083402

This article and any supplementary material should be cited as follows:

McClellan F, Washington M, Ruff R, Selkirk SM.
Early and innovative symptomatic care to improve quality of life of ALS patients at Cleveland VA ALS Center. J Rehabil Res Dev. 2013;50(4):vii-xvi. http://dx.doi.org/10.1682/JRRD.2013.05.0107

Researcher ID/ORCID: Stephen M. Selkirk, MD, PhD: F-3655-2011

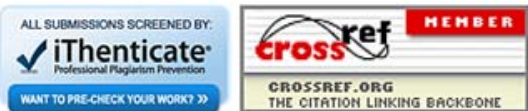

